\title{
PRESENCE OF NITRATE AND NITRITE IN COW FORAGE, PLASMA, AND MILK
}

\author{
M.D. CROITORU'a*, D.A. SzÉNÁSI ${ }^{\mathrm{a}}$ and I. FüLÖP \\ ${ }^{\text {a }}$ Department of Toxicology and Biopharmacy, University of Medicine and Farmacy of Tîrgu Mureş, \\ Gh. Marinescu street no. 38, 540138 Tîrgu Mureş. Romania
}

(Received: 3 June 2013; accepted: 22 November 2013)

Even if plants can contain high levels of nitrate and nitrite, milk and dairy products are not described as sources of these anions. The purpose of this paper was to measure the concentrations of nitrate and nitrite in forage, cow blood, and milk.

The results show that the nitrate ratio of milk to plasma is very low, suggesting that milk contamination with nitrate is unlikely to occur. This finding also proves the lack of an active transport mechanism to transfer nitrate from blood to milk. The nitrite anion almost disappears from milk through an enzymatic conversion; usually levels of $\mu \mathrm{g} 1^{-1}$ were measured.

Keywords: nitrate, nitrite, cow blood, milk, forage

High levels of nitrates and nitrites have been reported to be present in vegetal products and in some types of sausages (NAgy-Gasztonyi et al., 2006; SAntamaria, 2006; Leth et al., 2008).

Limiting the intake of nitrite and nitrate is necessary because of the toxicity of these anions. These anions in high amounts were linked with toxicological problems as: methaemoglobinaemia (GREER \& SHANNON, 2005), formation of carcinogenic N-nitrosamines (Mensinga et al., 2003; JAKSZYn \& GonZÁLez, 2006; Zeilmaker et al., 2010), neural tube defects (Li et al., 2011), and thyroid cancer (WARD et al., 2010).

There are only few data on the presence and fate of nitrate/nitrite in milk and dairy products despite the large number of recent articles regarding the presence of these anions in vegetal and meat products. Data regarding nitrate and nitrite content of animal forage is also missing from scientific literature despite the extensive tests made on vegetables used for human consumption.

Surveys show that milk and dairy products as dried milk and cheese do not contain toxicologically significant amounts of nitrate anion. Nitrate concentration in milk usually did not exceed the value of $5 \mathrm{mg} \mathrm{kg}^{-1}$ (Amariglio \& ImBert, 1980; Bintoro et al., 1996; SERAPHim \& De Siqueiera, 2000). Administration of potassium nitrate significantly increased the amount of nitrate in cow milk, but the concentration remained still under the safe consumption limit for an adult (36.4 $\mathrm{mg} \mathrm{l}^{-1}$ ) (BARANOvÁ et al., 1993). Unfortunately, no measurements of nitrate and nitrite in the blood of cows were made in order to observe how these anions are excreted in milk: through a passive or an active mechanism. Also, no measurements were made in animal forage to see how much the exogenous intake of these anions is.

\footnotetext{
* To whom correspondence should be addressed. Phone: +40-770-211-510; fax: +40-265-210-407; e-mails: croitorumircea@yahoo.com and croitoru.mircea@umftgm.ro.
} 
The purpose of this paper is to give data on concentrations of nitrite and nitrate in cow milk, blood, and forage, to establish how the nitrate/nitrite content of animal's forage can influence concentrations of these anions in cow's milk, and also to determine the ratio of milk to plasma concentration of these anions, as it would be an important marker of the active/ passive transport processes through which these anions can pass from blood into the milk.

\section{Materials and methods}

\subsection{Apparatus and reagents}

HPLC-UV/VIS configuration: Merck-Hitachi L-7000 series, LichroCART 250-4, Lichrospher 100, Rp-18 (5 $\mu \mathrm{m})$ Merck KgaA Column.

Griess A reagent: $50 \mathrm{mg}$ sulphanilic acid was dissolved using ultrasound in a mixture consisting of $1.5 \mathrm{ml}$ acetic acid and $3 \mathrm{ml}$ purified water. Griess B reagent: $4 \mathrm{mg}$ 1-naphtylamine was dissolved in $4 \mathrm{ml}$ acetic acid. Other reagents used, chromatographic conditions, and gradient elution program are described in detail elsewhere (CROITORU, 2012).

\subsection{Animals and tested samples}

Ten cows of "Bălţata românească" breed (also known as Romanian Spotted Cattle) with an average body mass of $596.3 \pm 41.4 \mathrm{~kg}$ were used in this experiment. The cows were not subjected to any other treatment than normally received during their animal husbandry process (feeding, milking, blood sampling for usual blood tests), and therefore in this experiment there was no need for an approval from our University's Commission on Ethics. Animal housing was made in accordance with international and local regulations.

Cow blood samples were obtained from veins located in the external ear in anticoagulant free polyethylene test tubes. Milk and blood samples were kept frozen $\left(-20^{\circ} \mathrm{C}\right)$ until analysis.

\subsection{Sample treatment}

Animal forage (hay, grass, ground corn, corn flour, bran, alfalfa, molasses): after sampling the products were frozen $\left(-20^{\circ} \mathrm{C}\right)$ until analysis. Three grams of every forage type was grinded, then mixed with $60 \mathrm{ml}$ of HPLC grade water and left in an ultrasonic bath for $60 \mathrm{~min}$. Two millilitres of the resulting suspension was centrifuged for $10 \mathrm{~min}$ at 11000 r.p.m. Of the supernatant $800 \mu \mathrm{l}$ was mixed with $800 \mu \mathrm{l}$ of acetonitrile (ACN) and centrifuged again. Also, $500 \mu \mathrm{l}$ of the supernatant was subjected to derivatization process.

Well water: $250 \mu \mathrm{l}$ of sample was mixed with $250 \mu \mathrm{l} \mathrm{ACN}$ and subjected to derivatization process.

Cow blood and milk samples: $500 \mu \mathrm{l}$ of liquid sample was mixed with $500 \mu \mathrm{l}$ of ACN. After centrifugation at 11000 r.p.m. the supernatant was subjected to the derivatization process (CROITORU, 2012).

Derivatization process: $500 \mu \mathrm{l}$ of liquid sample is mixed with $500 \mu \mathrm{l}$ of a $5 \mathrm{mM}$ tetrabutyl ammonium hydroxide solution adjusted to $\mathrm{pH} 2.5$ with sulphuric acid and $100 \mu$ l of Griess A reagent. After 1 minute $100 \mu \mathrm{l}$ Griess B reagent is added to the mixture. Samples could be analysed at any time between $30 \mathrm{~min}$ and $48 \mathrm{~h}$ (CROITORU, 2012). 


\section{Results and discussion}

\subsection{Performance of the analytical method}

We have previously published an HPLC-UV/VIS method suitable for the detection of low levels of nitrate and nitrite from blood samples and vegetables, which was intra-laboratory validated (CROITORU, 2012). Because milk can contain interfering agents, specificity retesting is needed using such matrices in order to avoid false readings. Figure 1 shows representative chromatograms obtained for a milk sample for the studied anions.

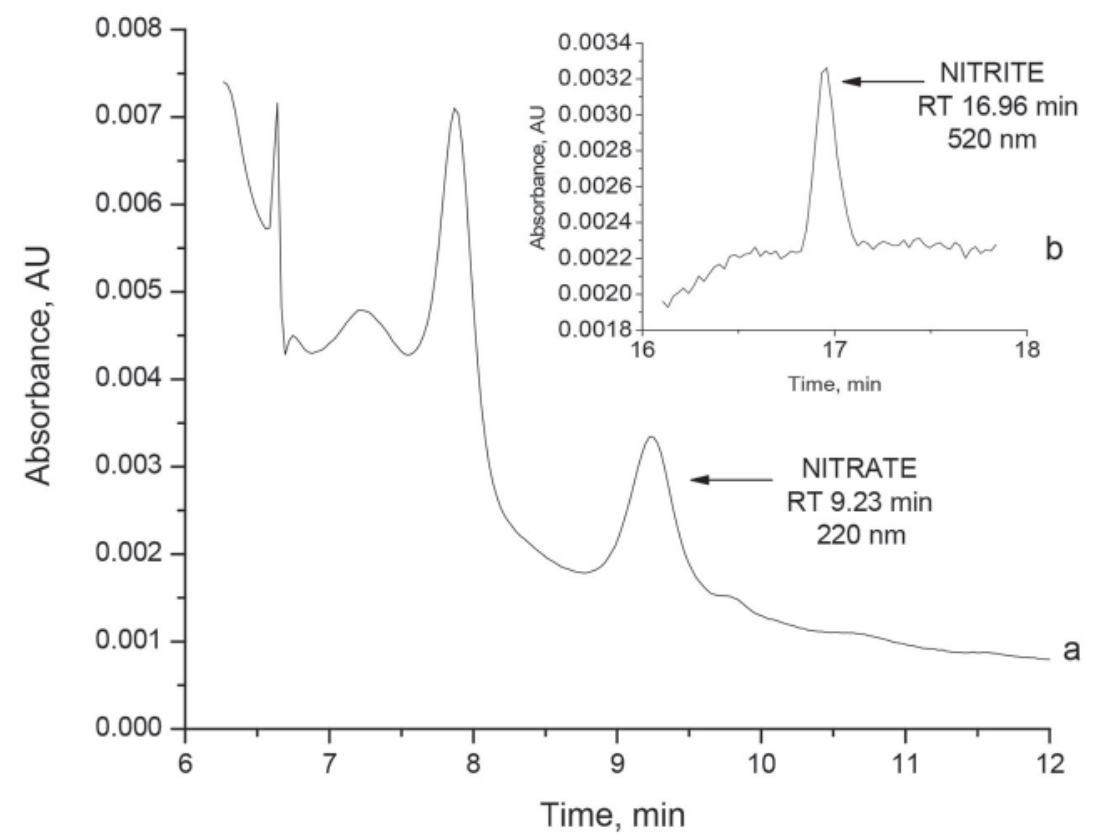

Fig. 1. Representative chromatograms obtained for a milk sample: a and b chromatograms are obtained with one injection using a dual wavelength recording. a: nitrate, RT 9,23 min, $220 \mathrm{~nm}$; b: nitrite, RT 16,96 min, $520 \mathrm{~nm}$

2.1.1. Specificity. Nitrate anion: since it is expected to be present in every milk sample, a blank is almost impossible to obtain. Peak identification based only on the retention time can lead to false readings. UV spectrum of the peak obtained from the DAD data (including the peak purity test) was used in order to increase the specificity of the method. Peak purity was in all cases higher than $97 \%$, showing that pure peaks were obtained. The peak purity tool is successfully applied for nitrate due to its characteristic absorption spectrum: very narrow, with a maximum of absorption at $216 \mathrm{~nm}$. It is true that other nitro derivatives will have an absorption spectrum similar to that of nitrate, but they will have a higher lipophilicity and thus a higher retention time than nitrate has.

Nitrite anion: in case of nitrite it is possible to obtain a blank by analysing the sample without adding one or both components of the Griess reagent.

No interferences were observed in the case of nitrate or nitrite when analysing milk or forage samples. 
2.1.2. Limits of detection and quantification. LOD (signal to noise ratio 1:3) and LOQ (signal to noise ratio 1:10) values for different types of samples are shown in Table 1. Differences between samples are due exclusively to differences in sample preparation.

Table 1. Limits of detection and quantification achieved in all samples tested for nitrate and nitrite anions

\begin{tabular}{|c|c|c|c|}
\hline \multirow{2}{*}{ Sample type } & \multicolumn{2}{|c|}{ Nitrate } & \multirow{2}{*}{$\begin{array}{l}\text { Nitrite } \\
\text { LOQ }^{1}\end{array}$} \\
\hline & $\mathrm{LOD}^{1}$ & $\mathrm{LOQ}^{1}$ & \\
\hline Milk & 0.06 & 0.20 & 2.0 \\
\hline Water & 0.06 & 0.20 & 2.0 \\
\hline Cow blood & 0.06 & 0.20 & 2.0 \\
\hline Animal forage & 1.20 & 4.00 & 40.0 \\
\hline
\end{tabular}

${ }^{1}$ Units for LOD and LOQ values are $\mathrm{mg} \mathrm{kg}^{-1}$ or $\mathrm{mg}^{-1}$ for nitrate and $\mu \mathrm{gg}^{-1}$ or $\mu \mathrm{g}^{-1}$ for nitrite

2.2. Measuring the intake and excretion through milk of nitrate and nitrite; estimation of milk/blood ratio of these anions

2.2.1. Nitrate and nitrite intake. Animal intake of nitrate and nitrite was evaluated in two different seasons: winter and summer. The water and every type of forage that was available to the cows were tested for nitrate and nitrite. Average intake of these anions together with the amount consumed by the cows and the concentrations in forage are shown in Table 2.

Table 2. Average forage intake (AFI) by animals during the experiment, forage nitrate concentration (FNitrateC), forage nitrite concentration (FNitriteC), and amount of nitrate (NitrateAC) and nitrite consumed (NitriteAC)

\begin{tabular}{|c|c|c|c|c|c|c|c|c|}
\hline \multirow[t]{2}{*}{ Forage type } & \multicolumn{2}{|c|}{ AFI (kg/cow/day) } & \multirow[t]{2}{*}{$\begin{array}{l}\text { FNitrateC } \\
\left(\mathrm{mg} \mathrm{kg}^{-1}\right)\end{array}$} & \multirow[t]{2}{*}{$\begin{array}{l}\text { FNitriteC } \\
\left(\mu \mathrm{g} \mathrm{kg}^{-1}\right)\end{array}$} & \multicolumn{2}{|c|}{$\begin{array}{c}\text { NitrateAC } \\
\text { (mg/cow/day) }\end{array}$} & \multicolumn{2}{|c|}{$\begin{array}{c}\text { NitriteAC } \\
\text { (mg/cow/day) }\end{array}$} \\
\hline & Winter & Summer & & & Winter & Summer & Winter & Summer \\
\hline Hay & 6.5 & - & 79.6 & 1.15 & 517.8 & - & 7.50 & - \\
\hline Ground corn & 23 & - & 0.0 & 0.31 & 0.0 & - & 7.21 & - \\
\hline Wheat bran & 1.5 & 1,5 & 15.6 & 0.24 & 23.5 & 23.5 & 0.37 & 0.37 \\
\hline Corn flour & $6-8$ & 4 & 20.28 & 0.64 & 142.0 & 81.1 & 4.50 & 2.57 \\
\hline Alfalfa & 5.5 & - & 4.67 & 0.65 & 25.7 & - & 3.61 & - \\
\hline Molasses & 2 & 1,5 & 0.05 & 0.01 & 0.1 & 0.1 & 0.01 & 0.01 \\
\hline Fresh grass & - & $35-40$ & 25.85 & 0.01 & - & 1034.2 & - & 0.56 \\
\hline Well water & $28-301$ & $40-451$ & 24.9 & 0.06 & 748.8 & 1076.1 & 1.82 & 0.85 \\
\hline $\begin{array}{l}\mathrm{TDI}^{1} \\
(\mathrm{mg} / \mathrm{cow})\end{array}$ & & & & & 1457.9 & 2215.0 & 25.02 & 4.36 \\
\hline $\begin{array}{l}\mathrm{DIA}^{2} \\
\left(\mathrm{mg} \mathrm{kg}^{-1}\right)\end{array}$ & & & & & 2.4 & 3.7 & 0.04 & 0.007 \\
\hline
\end{tabular}

${ }^{1}$ total daily intake (TDI $\left.-\mathrm{mg} / \mathrm{cow}\right){ }^{2}$ daily intake on average (DIA $-\mathrm{mg} \mathrm{kg}^{-1}$ ) of the studied anions during the tested period 
Despite the extensive literature data regarding the presence of nitrate and nitrite in vegetables used for human consumption, data on the presence of these anions in animal feed (grass, hay, alfalfa) is scarce and no comparison can be made with other studies. A high nitrate concentration is considered to be in herbage, exceeding $1.5 \mathrm{~g}$ nitrate $\mathrm{kg}^{-1}$ (WILSON et al., 2000).

2.2.2. Milk concentration of nitrate and nitrite. Milk sampling was done in the morning, at the first milking of cows, directly in the test tubes in order to prevent contamination of the sample with the tested anions. In order to have a better view of changes from day to day in the concentrations of nitrate and nitrite in milk, sampling was done at the same time on 5 consecutive days. Nitrate was detectable in all milk samples. Unfortunately, though our method has a better detectability than other published methods (BINTORO et al., 1996), not all samples contained nitrate above the LOQ. Milk concentrations of nitrate measured during this work are lower, but of the same order of magnitude with previously published concentrations (up to $2 \mathrm{mg} \mathrm{l}^{-1}$ ) (PRZYBYŁOWSKI et al., 1989) or in perfect agreement with more recent studies (KoRÉNEKOVÁ et al., 2000).

Data published in the literature state that nitrite is undetectable in the milk due to the enzymatic conversion of nitrite to nitrate (PrzybyŁowski et al., 1989; Silanikove et al., 2009). The method that we used is extremely sensitive to nitrite, thus the detection and measurement of nitrite is possible, even under enzymatic degradation. Concentrations of nitrite rarely exceeded the value of $10 \mu \mathrm{g}^{-1}$ in the tested samples.

Table 3 shows concentrations of nitrate and nitrite measured during 5 days of sampling and in two different seasons: winter and summer. Calculation of the mean and standard deviation is not feasible in summer because some of the concentrations were below the LOQ so no reasonable quantitative data could be calculated. No statistical differences were seen between cows in respect to their milk nitrate concentrations in winter. No statistical difference was seen between the sampling days regarding the nitrate content for the same season.

It is interesting to note that in winter concentrations of nitrate are significantly higher than those recorded in summer even if nitrate intake in winter is lower. This can be explained by changes brought in nitric oxide (important biomolecule; source of endogenous nitrate and nitrite) synthesis by the season changes. This change, even if statistically significant, could not be considered of toxicological importance. One can even observe that a small decrease in the analytical performance would make this difference imperceptible.

Using the average amounts of nitrate excreted in milk (amounts of milk produced by cows was about 30 1/day/cow) and the amount ingested through feed and water we calculated the percent of excretion in milk for nitrate anion. For concentrations below the LOQ, limit of detection value was used to calculate the average concentration in milk. The results show that only $0.75 \pm 0.21 \%$ of the amount of nitrate ingested is excreted through milk in winter, and this value is even lower in summer. Considering that an important pool of the body nitrate comes from an internal source (generation of nitric oxide), the percentage of nitrate excreted in milk is even lower.

Nitrite amounts were extremely low in the case of ingestion and milk secretion, so they were considered insignificant for the calculation of total inorganic oxidized nitrogen species consumed by animals and excreted through milk. 
Table 3. Concentrations of nitrate and nitrite measured in milk for 5 consecutive days and in two seasons

\begin{tabular}{|c|c|c|c|c|c|c|c|c|c|c|c|}
\hline \multicolumn{2}{|c|}{$\begin{array}{l}\text { Cow number } \\
\text { Anion conc. }\end{array}$} & 5982 & 6541 & 4720 & 4521 & 9716 & 9720 & 3551 & 9481 & 7318 & 4683 \\
\hline \multirow{10}{*}{$\begin{array}{l}\mathrm{NO}_{3}^{-} \\
\left(\mathrm{mg} \mathrm{l}^{-1}\right)\end{array}$} & \multirow[t]{5}{*}{ Winter } & 0.56 & 0.55 & 0.46 & 0.22 & 0.64 & 0.29 & 0.69 & 0.37 & 0.59 & $<0.2$ \\
\hline & & 0.51 & 0.42 & 0.26 & 0.32 & 0.37 & 0.31 & 0.47 & 0.30 & 0.37 & 0.20 \\
\hline & & 0.52 & 0.39 & 0.28 & 0.27 & 0.41 & 0.29 & 0.46 & 0.35 & 0.33 & 0.33 \\
\hline & & 0.49 & $<0.2$ & 0.20 & 0.43 & 0.30 & 0.31 & 0.42 & 0.20 & 0.36 & 0.24 \\
\hline & & 0.48 & 0.49 & 0.35 & 0.65 & 0.43 & 0.30 & 0.48 & 0.29 & 0.27 & 0.20 \\
\hline & \multirow[t]{5}{*}{ Summer } & 0.20 & 0.22 & $<0.2$ & $<0.2$ & $<0.2$ & $<0.2$ & $<0.2$ & $<0.2$ & 0.20 & 0.20 \\
\hline & & $<0.2$ & 0.20 & $<0.2$ & 0.26 & $<0.2$ & $<0.2$ & $<0.2$ & $<0.2$ & 0.20 & 0.20 \\
\hline & & $<0.2$ & 0.20 & $<0.2$ & 0.20 & $<0.2$ & $<0.2$ & $<0.2$ & $<0.2$ & $<0.2$ & $<0.2$ \\
\hline & & $<0.2$ & 0.20 & $<0.2$ & 0.20 & $<0.2$ & $<0.2$ & $<0.2$ & $<0.2$ & $<0.2$ & $<0.2$ \\
\hline & & $<0.2$ & $<0.2$ & $<0.2$ & $<0.2$ & $<0.2$ & $<0.2$ & $<0.2$ & $<0.2$ & 0.20 & 0.42 \\
\hline \multirow{10}{*}{$\begin{array}{l}\mathrm{NO}_{2}^{-} \\
\left(\mu \mathrm{g}^{-1}\right)\end{array}$} & \multirow[t]{5}{*}{ Winter } & 5.8 & 2.9 & 2.0 & 3.3 & 8.4 & 6.3 & 3.6 & 3.8 & 3.5 & 22.0 \\
\hline & & 4.5 & 2.4 & 2.4 & 3.0 & 8.8 & 2.6 & 4.3 & $<2.0$ & $<2.0$ & $<2.0$ \\
\hline & & 4.4 & 5.2 & $<2.0$ & 2.6 & 3.9 & 2.6 & 3.9 & 2.7 & 2.0 & $<2.0$ \\
\hline & & 4.9 & 10.6 & 2.0 & 4.2 & 4.7 & 2.0 & 3.5 & 5.2 & $<2.0$ & $<2.0$ \\
\hline & & 7.2 & 2.0 & 2.0 & $<2.0$ & 4.1 & 3.8 & 4.2 & 3.1 & $<2.0$ & 4.0 \\
\hline & \multirow[t]{5}{*}{ Summer } & 3.4 & 4.4 & 8.0 & 3.5 & 5.4 & 4.3 & 2.4 & 4.4 & 6.8 & 2.0 \\
\hline & & 10.2 & 6.5 & 13.8 & 21.0 & 6.4 & 4.7 & 4.3 & 7.2 & 7.2 & 2.7 \\
\hline & & 8.8 & 7.9 & 7.2 & 7.2 & 13.6 & 10.8 & 13.7 & 11.8 & 11.7 & 9.7 \\
\hline & & 51.6 & 2.4 & 16.7 & 13.1 & 2.0 & 12.2 & 7.5 & 45.2 & 32.5 & 12.1 \\
\hline & & 8.1 & 8.6 & 5.1 & 9.9 & 8.1 & 5.5 & $<2.0$ & 9.4 & 12.9 & 14.7 \\
\hline
\end{tabular}

${ }^{1}$ the official registration number of animals is given

2.2.3. Concentrations of nitrate and nitrite in cow's blood; milk/plasma ratio of these anions. In the scientific literature there is a lack of data on the concentration of nitrate and nitrite in blood of cow. During previous attempts only the sum of these anions was measured, without any speciation. Thus, previous tests were successful in measuring the sum of nitrate and nitrite only in calves, while for adult cows concentrations were below the LODs (BLuM et al., 2001).

During our research, venous blood was collected from cows immediately after milking, in summer. Concentration of nitrate and nitrite in the blood is shown in Table 4. Unexpectedly, low concentrations of nitrate were found in the blood of cow, $0.52 \pm 0.15 \mathrm{mg} \mathrm{l}^{-1}$ being their average. The average of nitrite concentrations was also very low, $24.4 \pm 6.1 \mu \mathrm{g} \mathrm{l}^{-1}$. 
Table 4. Nitrite and nitrate blood concentrations

\begin{tabular}{lccccccccccc}
\hline Cow number & 5982 & 6541 & 4720 & 4521 & 9716 & 9720 & 3551 & 9481 & 7318 & 4683 & average $\pm \mathrm{SD}$ \\
\hline $\mathrm{NO}_{3}^{-}\left(\mathrm{mg} \mathrm{l}^{-1}\right)$ & 0.25 & 0.64 & 0.80 & 0.47 & 0.60 & 0.34 & 0.58 & 0.49 & 0.53 & 0.50 & $0.52 \pm 0.15$ \\
$\mathrm{NO}_{2}^{-}\left(\mu \mathrm{g} \mathrm{I}^{-1}\right)$ & 26.4 & 27.7 & 24.7 & 20.4 & 17.3 & 38.7 & 26.9 & 20.5 & 20.3 & 21.6 & $24.4 \pm 6.1$ \\
\hline
\end{tabular}

Average milk to plasma ratios of nitrate range between $0.12 \pm 0.04$ and $0.42 \pm 0.15$ depending on the estimation made on the concentration of LOQ samples (one can consider the concentration closer to the LOD value or closer to the LOQ value). This milk to plasma ratio suggests the lack of a high activity transport mechanism to transfer nitrate from plasma in milk.

In the case of nitrite anion, calculation of milk to plasma ratio is not possible because of the enzymatic oxidation of this anion to nitrate; it is impossible to predict exactly how much nitrite is excreted in milk because its oxidation can begin even in the udder.

It can be seen that concentrations of nitrate and nitrite in cow's milk and their blood can be surprisingly low if their feed do not contain excessive amount of these anions. Milk to plasma ratio of nitrate is very low, suggesting the absence of a transport mechanism in the mammary gland. Because of this, it can be assumed that a contamination of milk through feed with high amount of nitrate could occur only when animals already show significant signs of nitrate toxicity.

\section{Conclusions}

Our work shows that natural occurrence of nitrite and nitrate in milk and dairy products is not a risk to human health. The transfer of nitrate from forage in cow milk can be considered insignificant, and the ratio of milk to plasma was also very low in the tested animals.

We proved that cow's mammary gland lacks an exporter type transport mechanism for nitrate. This means that milk from cows under a nitrate rich diet is expected to contain low amounts of nitrate.

Nitrite is present in all milk samples in extremely low concentrations, which are completely without toxicological significance to the human population.

This project was financed by the University of Medicine and Pharmacy of Tîrgu Mureş, internal grant number 30/11.12.2013.

\section{References}

Amariglio, S. \& Imbert, A. (1980): Survey on the nitrate-nitrite content of various dairy products. Ann. Nutr. Metab., 34, 1053-1060.

Baranová, M., Mal'A, P. \& Burdová, O. (1993): Transport of nitrates and nitrites into the milk of dairy cows through the digestive system. Vet. Med. (Praha), 38, 581-588.

Bintoro, V.P., Cantin-Esnault, D. \& Alary, J. (1996): A survey of nitrate contents in Indonesian milk by enzymic analysis. Fd Addit. Contam., 13, 77-87. 
Blum, J.W., Morel, C., Hammon, H.M., Bruckmaier, R.M., Jaggy, A., Zurbriggen, A. \& Jungi, T. (2001): High constitutional nitrate status in young cattle. Comp. Biochem. Physiol. A Mol. Integr. Physiol., 130, $271-282$.

Croitoru, M.D. (2012): Nitrite and nitrate can be accurately measured in samples of vegetal and animal origin using an HPLC-UV/VIS technique. J. Chromatogr. B Analyt. Technol. Biomed. Life Sci., 911, 154-161.

Greer, F.R. \& Shannon, M. (2005): Infant methemoglobinemia: The role of dietary nitrate in food and water. Pediatrics, 116, 784-786.

JAKSZYN, P. \& GoNZÁLEZ, C.A. (2006): Nitrosamine and related food intake and gastric and oesophageal cancer risk: A systematic review of the epidemiological evidence. World J. Gastroenterol., 12, 4296-4303.

Koréneková, B., Kottferová, J. \& Korének, M. (2000): The fat of added nitrate used in the manufacture of Emmental cheese. Food Addit. Contam., 17, 373-377.

Leth, T., Fagt, S., Nielsen, S. \& Andersen, R. (2008): Nitrite and nitrate content in meat products and estimated intake in Denmark from 1998 to 2006. Food Addit. Contam., 25, 1237-1245.

Li, Z.W., Zhang, L., Ye, R.W., Liu, J.M., Pei, L.J., Zheng, X.Y. \& Ren, A.G. (2011): Maternal periconceptional consumption of pickled vegetables and risk of neural tube defects in offspring. Chin. Med. J, 124, 1629-1633.

Mensinga, T.T., Speijers, G.J. \& Meulenbelt, J. (2003): Health implications of exposure to environmental nitrogenous compounds. Toxicol. Rev., 22, 41-51.

Nagy-Gasztonyi, M., Kardos-Neumann, Á. \& TakÁcs-Hásos, M. (2006): Characterization of red beet and carrot with special emphasis on nitrate accumulation. Acta Alimentaria, 35, 131-138.

PrzybyŁowski, P., Kisza, J., Janicka, B. \& Sajko, W. (1989): Wystepowanie azotanów i azotynów w mleku surowym W zalezności od systemu jego skupu. (Presence of nitrates and nitrites in raw milk as subject to the system of milk purchasing.) Rocz. Panstw. Zakl. Hig., 40, 6-15.

SANTAMARIA, P. (2006): Nitrate in vegetables: toxicity, content, intake and EC regulation. J. Sci. Fd Agric., 86, 10-17.

Seraphim, K.R \& De Siqueira, M.E. (2000): Nitrates and nitrites in homemade and industrial cheeses commercialized in the Southern region of Minas Gerais, Brazil. Arch. Latinoam. Nutr., 50, 87-90.

Silanikove, N., Shapiro, F., Silanikove, M., Merin, U. \& Leitner, G. (2009): Hydrogen peroxide-dependent conversion of nitrite to nitrate as a crucial feature of bovine milk catalase. J. Agric. Fd Chem., 57, 8018-8025.

Ward, M.H., Kilfoy, B.A., Weyer, P.J., Anderson, K.E., Folsom, A.R. \& Cerhan, J.R. (2010): Nitrate intake and the risk of thyroid cancer and thyroid disease. Epidemiology, 21, 389-395.

Wilson, W.S., BALl, A.S. \& Hinton, R.H. (2000): Managing risks of nitrates to humans \& the environment. Eur. J. Soil. Sci., 51, 541-549.

Zeilmaker, M.J., Bakker, M.I., Schothorst, R. \& Slob, W. (2010): Risk assessment of N-nitrosodimethylamine formed endogenously after fish-with-vegetable meals. Toxicol. Sci., 116, 323-335. 